\title{
AMNIOCENTESIS TRANSABDOMINAL Y EMBARAZO PROLONGADO
}

\author{
Dr. Fernando Sánchez Torres*
}

Se ha aceptado, de manera general, que el embarazo comienza a prolongarse cuando va más allá de los 294 días, es decir, de las 42 semanas de gestación $(16,20,21)$. Desafortunadamente el dato de la última menstruación, que es el parámetro utilizado en la práctica, no es un elemento digno de crédito para precisar la edad del embarazo. De ahí que cuando el parto no se ha realizado en los días esperados, el médico siempre pone en tela de juicio la fecha de la última regla suministrada por su paciente. Esta situación de duda, acompañada de una actitud pasiva o indiferente, puede resultar peligrosa para el feto pues no es improbable que se esté frente a un caso de gestación prolongada verdadera.

Aunque hay quienes dudan de la existencia del embarazo prolongado como una entidad clínica definida (10), lo cierto es que algunos niños producto de gestaciones que han ido más allá de las 42 semanas, nacen con signos claros de haber sufrido una agresión en la última etapa de su vida intrauterina.

Basado en este hecho, Clifford dedujo que la prolongación del embarazo podía acompañarse de un síndrome de disfunción placentaria, que era la causa de que los niños nacieran en condiciones críticas o murieran antes del parto $(5,6)$. Según la severidad del daño ocasionado por la postmadurez, Clifford estableció tres grados: En el primero la piel del niño muestra los efectos de la pérdida del vérnix, es decir, se observa seca, apergaminada, pero limpia de meconio; además el cabello es abundante y las uñas son largas. En el grado II ya hay manifestaciones de franca anoxia intrauterina, reflejada por la liberación de meconio que impregna los tegumentos fetales y la piel se encuentra exfoliada. En el grado III, que es la acentuación del anterior, el niño está deshidratado y puede dar la impresión de atrofia, además de que su piel está fuertemente teñida de meconio y macerada, especialmente en el escroto, planta de los pies y palma de las manos. Es natural que si no se procede a extraerlo, la muerte in utero vendrá prontamente.

Aceptando, pues, que toda prolongación cronológica de la gestación conlleva un peligro potencial para el feto, se ha tratado de encontrar un procedimiento que permita diagnosticar anteparto la edad del embarazo $y$ el estado fetal. Los rayos $X$ (4, 17), la citología vaginal (14, 15), la titulación de transaminasas séricas $(9,20)$, la biopsia placentaria (3), la dosificación de hormonas $(7,8$,

* Profesor Asociado del Departamento de Obstetricia y Ginecología. Facultad de Medicina de la Universidad Nacional. 
18), el estado clínico del cuello uterino (19), etc., no son, de manera alguna, elementos confiables. La inducción del parto, como conducta práctica para resolver el problema, también ha sido preconizada, $(1,20)$ y es, sin duda, el procedimiento que más se utiliza.

Si nembargo, muchas veces este proceder obliga a emprender inducciones en condiciones desfavorables, teniendo, por fracaso, que terminarse el parto con una operación cesárea, sin que en verdad hubiera existido una amenaza para el feto por causa de la dudosa gestación prolongada.

Considerando que la disminución del líquido amniótico y la presencia de meconio son signos de alarma en los casos de embarazos prolongados "verdaderos" o "patológicos", se han propuesto, con sentido práctico, dos sistemas para descubrirlos: la amnioscopia o histeroscopia $(2,12)$ y la amniocentesis $(11,13)$.

La amnioscopia permite observar a través del cuello uterino el polo inferior del saco amniótico. La comprobación de escaso líquido, sin vérnix, está a favor de una prolongación incipiente. Si existe meconio es ya una manifestación de anoxia, y según la homogeneidad de esa tinción puede presumirse el tiempo que lleva el feto en situación incómoda. Este método exploratorio, además de requerir el empleo de un aparato luminoso de endoscopia, se ve dificultado cuando el orificio cervical está cerrado. Por otra parte, no es infrecuente que durante el examen se rompan prematuramente las membranas ovulares.

La amniocentesis transabdominal es, indudablemente, un procedimiento sencillo que cada día tiene más utilización en la práctica obstétrica. Ejecutado adecuadamente no apareja mayores peligros, ni para la madre ni para el feto. Como recurso para aclarar las condiciones fetales en aquellos casos de probable embarazo prolongado, ha sido ya empleado (11, 13). Con el presente informe queremos dar a conocer nuestra experiencia y proponer una sistematización del manejo del embarazo prolongado, utilizando la amniocentesis transabdominal.

Como lo que se procura, al igūal que con la amnioscopia, es apreciar las características del líquido amniótico, deben, por eso, tenerse en cuenta la cantidad y el aspecto. En base a estos datos hemos clasificado el líquido en tres tipos:

Tipo I - Líquido abundante, con grumos de vérnix.

Tipo II - Líquido abundante, cetrino, sin vérnix.

Tipo III - Líquido escaso, teñido de meconio.

En el primer caso puede aceptarse que no existe ningún riesgo y debe permitirse que prosiga el embarazo. La punción se repetirá 10 a 14 días más tarde, si no se ha iniciado espontáneamente el trabajo de parto.

Si el líquido es de tipo II el riesgo es dudoso y deberá hacerse otra punción al cabo de 6 a 8 días. Si esta vez las características del líquido persisten, se hará nueva amniocentesis 6 días después.

La amenaza fetal se considerará establecida si el líquido es de tipo III, procediéndose, por lo tanto, a provocar el parto. Si el cuello es muy favorable se puede iniciar la inducción, vigilando a cortos intervalos la frecuencia cardíaca. La alteración de 
esta después de cada contracción obliga a practicar cesárea.

También tiene cabida la operación desde un principio, si el cuello es desfavorable (inmaduro).

En los casos de líquido tipos I y II, queda a juicio del obstetra practicar la inducción, si el cuello está maduro.

\section{Material y Métodos}

Hemos estudiado 30 pacientes cuyo embarazo había ido más allá de las 42 semanas, tomando como punto de partida 10 días después de haberse iniciado la última menstruación. De ellas 18 eran pacientes del Instituto Materno Infantil (IMI), 8 de clientela privada y 4 adscritas al Instituto Colombiano de Seguros Sociales (ICSS).

Todas manifestaron su preocupación por el hecho de que su embarazo "se hubiera pasado de tiempo"; temían, además, que algo malo fuera a sucederle a su hijo. Para despejar esta justa incertidumbre se les propuso el procedimiento de la amniocentesis transabdominal, el cual siempre fue aceptado. La punción se hizo bajo las siguientes condiciones: Estando la paciente en decúbito dorsal, y previa evacuación espontánea de la vejiga, se identificaron por palpación la situación, presentación y posición del feto. Luego se procedió a lavar y desinfectar la pared abdominal, como si fuera a practicarse una laparotomía. Sin anestesia ni analgesia alguna, con una aguja de punción lumbar calibre 19 ○ 20, se hizo la amniocentesis al lado donde se hallaban las pequeñas partes fetales, unos centímetros hacia afuera del ombligo. Una vez que se tuvo la sensación de que la aguja estaba en la cavidad amniótica, se retiró el mandril. Siempre el líquido brotó es- pontáneamente cuando era abundante. En caso contrario se obtuvo aspirando con una jeringa. En tres ocasiones apareció sangre (punción placentaria) lo cual obligó a practicar una nueva punción en otro sitio.

\section{Resultados}

En 21 ocasiones el aspecto del líquido demostró que no existía ningún riesgo (tipo I). En 3 pacientes se repitió la punción a los 10, 12 y 14 días, observándose otra vez en todos el líquido normal. A una de ellas se le hizo una tercera punción a los 20 días, apreciándose un líquido de tipo II. El parto de las mujeres de este grupo se sucedió de 2 a 23 días después de la primera amniocentesis, iniciándose espontáneamente en 15 (recién nacidos con calificación de Apgar de 10/10), dos mediante inducción hormonal por existir cuello maduro y 4 con cesárea ( 3 por cesáreas previas y la otra por estrechez pélvica). En ninguno de los niños se apreciaron manifestaciones de postmadurez.

En 6 casos el líquido fue de tipo II (amenaza dudosa). En una paciente se repitió la punción al séptimo día y el líquido continuaba del mismo aspecto, sin vérnix. Tuvo un parto espontáneo dos días más tarde. En todos el parto se inició espontáneamente, de 1 a 9 días después de la primera punción. Los niños nacieron con una calificación de Apgar de 10/10, pero uno mostró un síndrome de Clifford grado I (embarazo de 43 semanas).

Sólo en 3 oportunidades el líquido fue de tipo III (riesgo establecido). El parto tuvo lugar dentro de las primeras 24 horas de practicada la punción. Veamos cada uno de ellos: 
CASO 1 - (ICSS). Secundigestante, amenorrea de 44 semanas, altura uterina $29 \mathrm{~cm}$., cuello inmaduro. Se obtiene líquido escaso, teñido fuertemente de meconio. De manera inmediata se procede a practicar cesárea. Nace una niña de 3.200 gr., piel exfoliada e impregnada de meconio (síndrome de Clifford grado II, calificación de Apgar 6/10).

CASO 2 - (IMI). Primigestante, amenorrea de 44 semanas, altura uterina de $32 \mathrm{~cm}$., cuello inmaduro. Líquido teñido de meconio y sangre. Mediante operación cesárea se obtiene un niño de 3.400 gr., con calificación de Apgar de $4 / 10$ y síndrome de Clifford grado II.

CASO 3 - (IMI). Secundigestante, 45 semanas de amenorrea, altura uterina $31 \mathrm{~cm}$. , cuello inmaduro. Líquido escaso, meconiado. Se inicia inducción con infusión oxitócica pero a las dos horas se practica cesárea por bradicardia fetal. Nace un niño de 2.700 gr., Apgar de 4/10 y sindrome de Clifford grado II.

\section{Resumen}

El autor propone practicar sistemáticamente amniocentesis transabdominal cuando el embarazo se ha prolongado más de 42 semanas. La conducta a seguir estará sujeta a las características del líquido amniótico, así:

Tipo 1 - Líquido abundante, con vérnix.

Tipo II - Líquido más o menos abundante, de color cetrino, sin vérnix.

Tipo III - Líquido escaso, teñido de meconio.

En los dos primeros tipos debe permitirse la continuación del embarazo y practicar nuevas punciones a intervalos prudentes.

En los casos de líquido tipo III debe procederse inmediatamente a evacuar el útero.

\section{Summary}

The author proposes the systematical practice of trans-abdominal am- niocentesis when pregnancy exceeds 42 weeks. The process to be followed shall be subject to the characteristics of the amniotic liquid, to wit: nix.

Type I - Abundant liquid, with ver-

Type II - More or less abundant liquid, of a citrine color, lacking vernix.

Type 111 - Scarce liquid, tinted by meconium.

The continuation of the pregnancy must be allowed in the case of the above two first types and new punctures must be performed at advisable intervals.

In the cases of Type III liquid, the evacuation of the uterus must be performed immediately.

\section{BIBLIOGRAFIA}

1 Aguero, O. y ROMERO, A. Rev. Obs. Gin. Venezuela. 19: 307, 1954.

2 AGUERO, O. y AURE, M. Ginec. Obstet. Méx. 27: 629, 1970.

3 ALVAREZ, H.; BEJAR, R.; ALADJEM, S.; ALVAREZ, C.; REMEDIO, M. R. Y SICA, Y. "La placenta humana". Mem. IV Congr. Uruguayo Ginecot. Tomo I, Pág. 190, 1964.

4 BROWN, J. C. Am. J. Obst. \& Gynec. 85 : 573, 1963.

5 CLIFFORD, S. H. J. Pediat. 44: 1, 1954.

6 CLIFFORD, S. H. J.A.M.A. 165: 1663, 1957.

7 DANIELSSON, M. Am. J. Obst. \& Gynec. 91 : 895, 1965.

8 DE LA FUENTE, F. y VISCAINO, G. D. Toko-Gin. Pract. 18: 152, 1959.

9 HERRERA, M.; DE LA FUENTE, S. ; UGARTE, G. y LORCA, F. Rev. Chilena de Obst. y Gin. 27: 141, 1962.

10 HOLMES, R. Am. J. Obst. \& Gynec. 56 : 167, 1948.

11 IGLESIAS, J.; MERY, A. Y LEIXEKARD, P. y BARDI, E. Memorias $\vee$ Congreso FLASOG (Viña del Mar), Pág. 652, 1966. 
12 JANTZEN, K. Landarzt 16: 665, 1965.

I3 LEON, D. ; LEIBASCHOFF, J.; DAMASCO, L. y SANTIAGO, M. Memorias XIV Reunión FASGO (Mendoza), Pág. 491, 1966.

14 LICHTFUS, C.; PUNDEL, J. P. y GANDAR, R. Gynec. et Obst. 57: 380, 1958.

15 MANFREDI, P. Gazz. Int. 67: 1826, 1962.

16 NESBITT R. E. L. Obst. \& Gynec. 8: 157, 1956.
17 RACKER, D. ; BURGESS, G. H. y M9NLY, G. Lancet. 2: 953, 1953.

18 RAMIREZ C. Bol. Soc. Chilena Obst. Gin. 18: 101, 1953.

19 RATHBUN, L. S, Am. J. Obst. \& Gynec. 46: 278, 1943.

20 SANCHEZ, F. Memorias V Congreso FLASOG (Viña del Mar), Pág. 65, 1966.

21 STRAND, A. Acta Obst. et Gynec. scandinav. 35: 76, 1956. 